\title{
Coronavirus 2019 infection in people with associated co-morbidities: case fatality and ACE2 inhibitors treatment concerns
}

\author{
Rokhsareh Aghili ${ }^{1}$, Maryam Honardoost ${ }^{1 *}$, Mohammad E Khamseh ${ }^{1}$
}

1-Rokhsareh Aghili ${ }^{1}$ MD.Ph.D

Endocrine Research Center. Institute of Endocrinology and Metabolism. Iran University of Medical Sciences, Tehran, Iran.

Address; No 10, Firoozeh St, Vali-asrSq,Tehran, Iran.

Aghili.R@iums.ac.ir

2- Maryam Honardoost ${ }^{1}$. Ph.D

Endocrine Research Center. Institute of Endocrinology and Metabolism. Iran University of Medical Sciences, Tehran, Iran

Address; No 10, Firoozeh St, Vali-asrSq,Tehran, Iran.

Honardoost.m@iums.ac.ir

3-Mohammad E Khamseh ${ }^{1}$ MD

Endocrine Research Center. Institute of Endocrinology and Metabolism. Iran University of Medical Sciences, Tehran, Iran.

Address; No 10, Firoozeh St, Vali-asrSq,Tehran, Iran.

Khamseh.m@iums.ac.ir

\section{*Correspondence:}

Maryam Honardoost, Assistant professor of Molecular Medicine, Endocrine Research Center, Institute of Endocrinology and Metabolism, Iran University of Medical Sciences, Tehran,

Address; No 10, Firoozeh St, Vali-asrSq,Tehran, Iran.

Website;http://www.iums.ac.ir/link/iem

Tel:+982188945246

Email: honardoost.m@iums.ac.ir

maryamil79@gmail.com 


\title{
Coronavirus 2019 infection in people with associated co-morbidities: case fatality and ACE2 inhibitors treatment concerns
}

\begin{abstract}
The Corona Virus Disease 2019 (COVID-19) outbreak is becoming pandemic with the highest mortality in people with associated comorbidities. These RNA viruses containing four structural proteins usually use spike protein to enter the host cell. It has been demonstrated that Angiotensin Converting Enzyme 2 (ACE2) , as a part of renin-angiotensin-aldosterone system (RAAS), acts as a host receptor for the virus which is the main target of therapeutic approaches. However, medications acting on RAAS can lead to serious complications especially in people with diabetes and hypertension. To avoid this, other potential treatment modalities should be used in COVID-19 patients with associated comorbidities.
\end{abstract}

Keywords: COVID-19, Associated comorbidities, Treatment, ACE2 inhibitors, Type 2 diabetes. 


\section{Coronavirus 2019 infection in people with associated co-morbidities: case fatality and ACE2 inhibitors treatment concerns}

\section{Introduction}

One of the major challenges in the $21^{\text {st }}$ century is the spread of emerging infectious diseases, namely, the ongoing new coronavirus pneumonia (Corona Virus Disease 2019, COVID-19) outbreak. COVID-19 as the latest infectious diseaseis becoming pandemic [1-3]. Coronaviruses identified in the mid-1960s cause disease in humans and a variety of animals; SARS-CoV, and MERS-CoV are two coronaviruses causing outbreaks in humans[4]. Genetic analysis revealed that COVID-19 highly looks like the severe acute respiratory syndrome (SARS) [1, 5]. It genetically clusters within the genus betacoronavirus [4]; however, discordant clustering with the Bat SARS-like coronavirus sequences have been detected [5]. There is evidence that COVID-19 is not-mosaic with a distinct lineage in almost half of its genome within the betacoronavirus[5].

The 53th COVID-19 Situation Report of World Health Organization(WHO) on March, 13, 2020, reported 32758 diagnosed cases with 4955deaths worldwide [6].

\section{COVID-19 infection and Case fatality estimates}

WHO -China Joint Mission group reported that among 55,924 laboratory confirmed cases, 2114 cases died since 20 February,2020 (Crude Fatality Ratio[CFR]: 3.8\%). Demographic factors, namely age and sex are risk factors for COVID-19 infection. The highest mortality is reported among people over 80 years of age (CFR 21.9\%) and in men (4.7\% vs. 2.8\%)[7].The lower risk in women could be justified by the plausible protective effect of $\mathrm{X}$ chromosome and sex hormones having a significant contribution in innate and adaptive immunity[8]. Furthermore, obesity and presence of comorbidity are associated with significant increase in mortality[8]. The 
CFR is higher in the presence of hypertension (CFR: 8.4\%), diabetes (CFR: 9.2\%), cardiovascular disease (CFR: 13.2\%), chronic respiratory disease (CFR: 8\%) and cancer (CFR: $7 \%$ ). This could be explained by the weaker immune function $[7,8]$, while in people without any comorbidity, the CFR was reported to be $1.4 \%[7]$.

In the other report by Chinese Center for Disease Control and Prevention, the CFR was reported to be $0.9 \%$ among patients without comorbidity while this figure was $10.5 \%$ for those with cardiovascular disease, $7.3 \%$ for diabetes, $6.3 \%$ for chronic respiratory disease, $6.0 \%$ for hypertension, and $5.6 \%$ for cancer[3].

Based on previous published data, the prevalence of important COVID-19 co-morbid conditions was summarized in table 1 . Chen et al found that, about $50 \%$ of patients infected withCOVID-19 had a comorbidity mainly cardiovascular/cerebrovascular diseases(40\%) and diabetes (12.12\%)[3].

Denget al. reported that among 41 patients who had confirmed COVID-19, 30 (73\%) were men by Jan 2, 2020 and less than50\% had underlying diseases (13 [32\%]) such as diabetes (8 [20\%]), hypertension (6 [15\%]), and cardiovascular disease (6 [15\%]) showing that underlying diseases are crucial factors resulted in death of COVID-19 patients $[9,10]$.

In a study on 138 patients, 102 patients did not receive ICU care while 36 people required ICU care due to older age (median age, 66 years [IQR, 57-78] vs. 51 years [IQR, 37-62]; $P<0.001)$, having underlying diseases such as hypertension (21 [58.3\%] vs. 22 [21.6\%], diabetes $(8[22.2 \%]$ vs. $6[5.9 \%])$, cardiovascular disease (9 [25.0\%] vs. $11[10.8 \%])$, and cerebrovascular disease $6[16.7 \%]$ vs. $1[1.0 \%])[11]$.

Several studies has been reported that $38.7 \%$ to $64.3 \%$ of diagnosed COVID-19 patients had at least one chronic medical illness which diabetes and hypertension were the most prevalent comorbidities (table 1)[12, 13]. 
Table 1: Prevalence of important comorbid conditions

\begin{tabular}{|c|c|c|c|c|c|c|}
\hline $\begin{array}{l}\text { Laboratory confirmed } \\
\text { cases }(\mathrm{N})\end{array}$ & $\begin{array}{l}\text { Cardiovascular } \\
\text { disease } \\
\% \\
\end{array}$ & $\begin{array}{l}\text { Diabetes } \\
\%\end{array}$ & $\begin{array}{l}\text { Hypertension } \\
\%\end{array}$ & $\begin{array}{l}\text { Chronic } \\
\text { respiratory } \\
\text { disease\% }\end{array}$ & $\begin{array}{l}\text { Cancer } \\
\%\end{array}$ & ref \\
\hline 41 & 15 & 20 & 15 & - & - & {$[10$} \\
\hline 26 & 19.2 & 42.3 & 53.8 & 19.2 & - & [9] \\
\hline 138 & 14.5 & 10.1 & 31.2 & - & 7.2 & {$[11$} \\
\hline 36 (ICU admitted) & 25 & 22.2 & 53.8 & - & - & {$[11$} \\
\hline 102 & 10.8 & 5.9 & 21.6 & - & - & {$[11$} \\
\hline 9 & - & 11.11 & - & - & - & {$[38$} \\
\hline 140 & - & 12.1 & 30 & & - & {$[12$} \\
\hline 1099 & 2.5 & 7.4 & 15 & 1.1 & 0.9 & {$[13$} \\
\hline 926 (non severe ) & 1.8 & 5.7 & 13.4 & 0.6 & 0.8 & {$[13$} \\
\hline 173 (severe) & 5.8 & 16.12 & 23.7 & 3.5 & 1.7 & {$[13$} \\
\hline 99 & 40 & 12.12 & - & - & 1 & [8] \\
\hline 44,672 & 4.2 & 5.3 & 12.8 & 2.4 & 0.5 & [3] \\
\hline
\end{tabular}

\section{COVID-19 virus exploited host ACE2 receptor}

Coronaviruses are RNA viruses containing at least four structural proteins including the membrane, envelope, spike, and nucleocapsid protein [5, 14]. During virus infection, spike facilitates attachment to cellular receptor or attachment factors [15-17].Angiotensin Converting Enzyme 2 (ACE2) as one of the membrane exopeptidase acts as a host receptor for COVID-19 to enter the human cells[4, 18]. ACE2 as a part of renin-angiotensin-aldosterone system (RAAS)regulates vasoconstriction, sodium reabsorption, and electrolytebalance resulting in blood pressure control [16]. Within the RAAS, angiotensin (Ang) I is converted into the vasoconstrictor Ang II by ACE, while ACE2 counterbalance the pathway with great affinity to Ang II and transform it to vasodilator Ang 1-7 [16].Michael Letko et al. demonstrated that COVID-19 may enter the cell by expressing human ACE2, confirming the role of ACE2 in virus infection [14].High expression of ACE2 in oral cavity and specifically epithelial cells of tongue explains the reason for susceptibility of oral cavity for COVID-19 infection. ACE2 is also highly expressed in lung, esophagus, ileum, colon, cholangiocytes, myocardial cells, renal proximal tubule cells, and bladder urothelial cells indicating these organs can be affected by COVID-19 
infection [19]. However, its role in development of lung injury in SARS-Cov infection was controversial because of down-regulation of ACE2 expression as infection initiated [12]. It might have dual effects: one as a receptor for virus entrance, and then, as a lung injury promoter by down-regulation [12].

\section{Treatment modalities targeting host cell receptor and virus entry}

No specific medication or vaccine has been made against COVID-19 yet[20]. Two classes of medications are currently used in COVID-19; one targeting human immune system and the other acting on coronavirus itself[17]. Considering the potential routes of SARS-CoV-2 entrance to the host cell, effective therapeutic option can be based on the virus-host cell receptor interaction in order to inhibit the virus entry. As mentioned earlier, the virus makes use of ACE2 as a receptor to enter the cell; therefore, targeting ACE2binding may prevent COVID-19infection [4, 19, 21].Chloroquine, an old drug used to treat malaria, amoebiosis, HIV, and autoimmune diseases, has been effective in treatment of COVID-19 [22, 23]. It acts via increasing endosomal $\mathrm{pH}$ required for viral entrance to the cell. Furthermore, it interferes the glycolysation of ACE2 (impairment of terminal glycosylation) leading to less affinity between ACE2 and SARS-CoV spike protein as well as inability of virus to attach cell and therefore preventing infection initiation [22]. On the other hand, An effective and safe approach is passive immunization [24]. Monoclonal antibodies are the important class of medications in immunotherapy with higher specificity, purity, safety, and low risk of contamination compared to serum therapy and intravenous immunoglobulins. Considering the results of the study conducted by Khan et al on patients with ARDS, GSK2586881, a recombinant human ACE2 (rhACE2), resulted in a decrease in plasma Ang II and IL-6 and increase in Ang 1-7 [25, 26]. Therefore, it could potentially be used for severe COVID-19.Viral/ host-targeted agents and their mechanism of action are summarized in table 2. 


\begin{tabular}{|c|c|c|c|}
\hline Infectious diseases & Antiviral agents & Reported mechanism of action & action Status \\
\hline $\begin{array}{l}\text { 2019-nCoV, } \\
\text { MERS-CoV }\end{array}$ & Nafamostat & Inhibits spike-mediated membrane fusion & $\begin{array}{l}\text { Approved for anticoagulant therapy in } \\
\text { Asian countries }\end{array}$ \\
\hline SARS-CoV & $\begin{array}{l}\text { Griffithsin } \\
\text { (red-alga-derived } \\
\text { lectin) }\end{array}$ & $\begin{array}{l}\text { Inhibits viral entry. Docking results showed that } \\
\text { glycyrrhizin has the potential biding to ACE2. }\end{array}$ & $\begin{array}{l}\text { Phase I for the prevention of HIV } \\
\text { transmission }\end{array}$ \\
\hline SARS-CoV & $\begin{array}{l}\text { Glycyrrhizin } \\
\text { (liquorice root) }\end{array}$ & $\begin{array}{l}\text { Inhibits viral entry. Docking results showed that } \\
\text { glycyrrhizin has the potential biding to ACE2. }\end{array}$ & $\begin{array}{l}\text { Clinical trials for treatment of liver } \\
\text { diseases [63] }\end{array}$ \\
\hline $\begin{array}{l}\text { SARS-CoV, } \\
\text { MERS-CoV, } \\
\text { Influenza }\end{array}$ & Peptide (P9) & $\begin{array}{l}\text { Inhibits spike protein-mediated } \\
\text { cell-cell entry or fusion }\end{array}$ & Preclinical \\
\hline $\begin{array}{l}\text { HCoV (e.g. } \\
\text { MERS, SARS }\end{array}$ & $\begin{array}{l}\text { OC43-HR2P (most } \\
\text { promising EK1) }\end{array}$ & Inhibits pan-CoV fusion & Preclinical \\
\hline HCoV-229E & $\begin{array}{l}\text { 229E-HR1P } \\
\text { 229E-HR2P }\end{array}$ & $\begin{array}{l}\text { Inhibits spike protein-mediated } \\
\text { cell-cell fusion }\end{array}$ & Preclinical \\
\hline $\begin{array}{l}\text { HCoV, Influenza } \\
\text { virus }\end{array}$ & $\begin{array}{l}\text { 1-thia-4-azaspiro } \\
\text { [4.5] decan-3-one } \\
\text { derivatives } \\
\text { (Compound } 8 n \text { ) }\end{array}$ & - & Preclinical \\
\hline $\begin{array}{l}\text { 2019-nCoV } \\
\text { SARS-CoV } \\
\text { MERS-CoV }\end{array}$ & Chloroquine & $\begin{array}{l}\text { Elevates the endosomal } \mathrm{pH} \text {, and appears to } \\
\text { interfere with terminal glycosylation of ACE } 2 \text {. } \\
\text { Thus affects the viral fusion and trafficking } \\
\text { events. }\end{array}$ & $\begin{array}{l}\text { Approved for malaria and certain } \\
\text { amoeba infections Open-label trial for } \\
\text { 2019-nCoV (ChiCTR2000029609) }\end{array}$ \\
\hline $\begin{array}{l}\text { SARS-CoV } \\
\text { 2019-nCoV }\end{array}$ & SSAA09E2 & $\begin{array}{l}\text { Blocks early interactions of SARS-S with the } \\
\text { receptor for ACE2 }\end{array}$ & Preclinical \\
\hline $\begin{array}{l}\text { SARS-CoV } \\
\text { 2019-nCoV }\end{array}$ & SSAA09E3 & $\begin{array}{l}\text { Prevents fusion of the viral membrane with the host } \\
\text { cellular membrane }\end{array}$ & Preclinical \\
\hline $\begin{array}{l}\text { SARS-CoV } \\
\text { 2019-nCoV }\end{array}$ & NAAE & $\begin{array}{l}\text { Inhibits both ACE } 2 \text { catalytic activity and S-protein- } \\
\text { induced cell-cell fusion }\end{array}$ & Preclinical \\
\hline SARS-CoV-2 & TMPRSS2 inhibitor & $\begin{array}{l}\text { Inhibits viral } S \text { protein cleavage and does not } \\
\text { allow the fusion of viral and cellular membranes }\end{array}$ & $\begin{array}{l}\text { The protease inhibitor camostat } \\
\text { mesylate, which blocks TMPRSS } 2 \\
\text { activity has been approved in Japan for } \\
\text { human use, but for an unrelated } \\
\text { indication. }\end{array}$ \\
\hline Coronavirus & R80-GSK2586881 & $\begin{array}{l}\text { Recombinant human ACE2 which resulted in a } \\
\text { rapid decrease in plasma Ang II levels and increase } \\
\text { in Ang 1-7 levels }\end{array}$ & $\begin{array}{l}\text { Phase II trial examining the safety and } \\
\text { efficacy in patients with ARDS. }\end{array}$ \\
\hline
\end{tabular}

Table 2: Summary of Potential antiviral agents against COVID-19 based on targeting virus-receptor binding and virus entry 


\subsection{ACE2 based therapy: the link between infection susceptibility and treatment complications}

Under-glycosylation of ACE2by using Chloroquine may prevent virus infection. On the other hand, it may interfere the normal function of ACE2 leading to cardiovascular complications [27, 28]. ACE2 dysfunction results in elevated concentration of Ang II it then increase oxidative stress and inflammation which could lead to development of metabolic syndrome, diabetes, and diabetes-related complications[27]. Therefore, ACE2/Ang(1-7) pathway has the protective effect in patients with type 2 diabetes and can be a treatment strategy in Ang-II-mediated T2DM through modulating blood glucose by adjustingthe levels of Ang II and/or Ang-(1-7) in pancreatic cells and regulating insulin secretion [29-31](Fig 1).

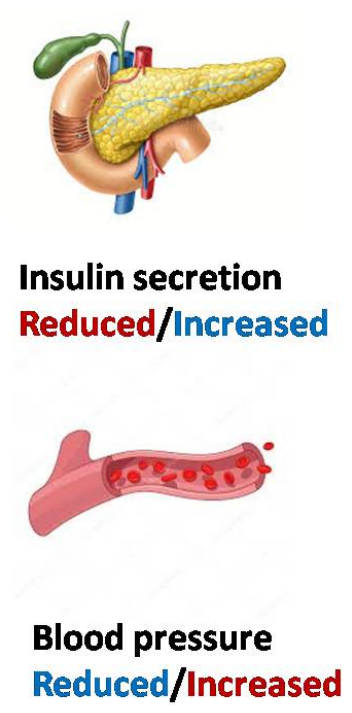

Reduced/Increased
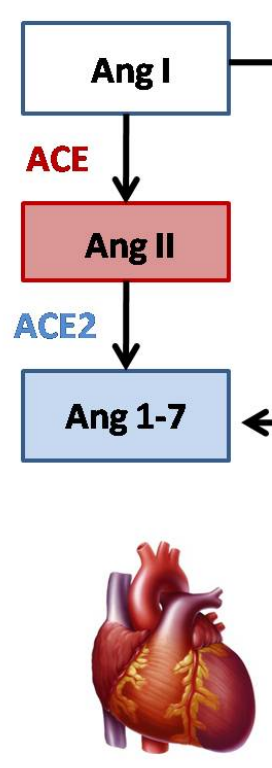

\section{Cardiomyopathy} Reduced/Increased
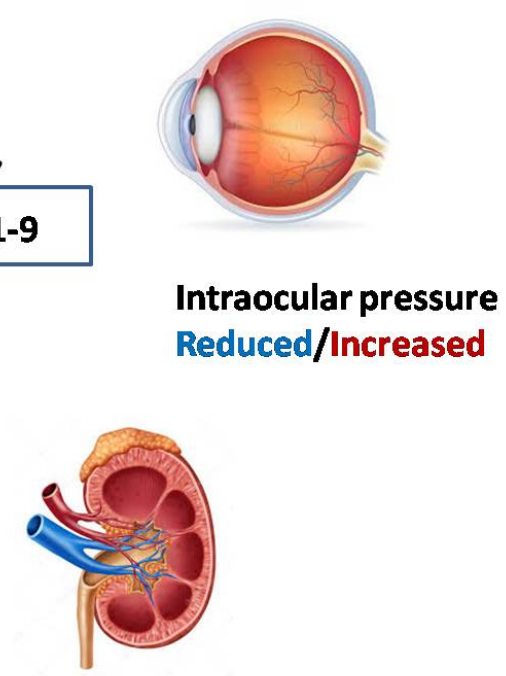

Glomerular filtration rate Reduced/Potentially improved

Fig1 :RAAS and ACE/ACE 2 effects on T2D and associated complications 


\subsection{Diabetic Cardiomyopathy}

Cardiovascular disease is highly prevalent in patients with diabetes compared to the general population. RAAS activation and imbalance in ACE-Ang II and ACE2-Ang 1-7 are highly accused in this process [16].High blood glucose can promote local Ang II production in heart tissue. RAAS is also up-regulated in diabetes leading to activation of AngII pathway and subsequently inflammation, increased oxidative stress, cell proliferation as well as apoptosis, and fibrosis which contribute to cardiac remodeling and atherosclerosis. While, ACE2 improves cardiac function by preventing myocardial fibrosis, reducing remodeling and the development of left ventricular hypertrophy as well as pressure-overload-induced heart failure [21].Therefore, RAAS inhibition by ACE inhibitors and angiotensin II receptor blockers has been recommended as the first line therapy in CVD in people with diabetes by lowering target-organ damageas well as controlling blood pressure[16, 21](Fig 1).

\subsection{Diabetes and Hypertension}

ACE2 is also present in endothelium of blood vessels; therefore, its reduction could result in increased Ang II level thus contributing to elevated blood pressure [32]. In a study on rats it was shown that overexpression of ACE2 in the blood vessels improved endothelial function leading to reduced blood pressure, whileACE2 deficiency may contribute to increased systolic blood pressure[32, 33].Furthermore, central hypertension has been shown to be affected by the level of ACE2 [33]. Therefore, ACE2 replenishing may be a significant therapeutic approach against diabetic hypertension.

\subsection{Diabetic Nephropathy}

Diabetic nephropathy is a micro-vascular diabetes related complication associated with CVD risk in people with diabetes. Normally, ACE2 is expressed in the kidney predominantly at the luminal 
brush border of the proximal tubule, while in people with diabetic nephropathy as well as other forms of chronic kidney disease ACE2 expression may down-regulate resulting in albuminuria or tubular injury; therefore, further renal injury will happen with more ACE2 inhibition[33]. In a study conducted by Harris et al, the ACE/ACE2 ratio was found to be increased in both glomerulus and tubulointerstitiumof patients with diabetic nephropathy, mostly due to reduced ACE2 expression[34]. Another study on diabetic mice demonstrated that total ACE2 reduction/deletion as well as pharmacologic ACE2 inhibition may result in diabetic nephropathy [29]. While ACE2 can reduce the progression of diabetic nephropathy by direct effect on glomerulus [34](Fig 1).

\section{5..Diabetic Retinopathy}

The most prevalent micro-vascular diabetes related complication is diabetic retinopathy (DR) in which abnormal activity of the RAAS has an essential role [27].In contrast, overexpression of ACE2/Ang-(1-7) may have protective role against DR [35].Animal studies revealed ACE2 as the counter-regulator of Ang II can reduce the intra-ocular pressure in addition to inflammatory process $[27,36]$. In line with the results, treatment with recombinant ACE2 could decrease inflammatory process as well as reducing a cellular capillaries and preventing retinal ganglion cell loss [36]. Therefore, it seems that increasing the bioavailability of ACE2 has a critical role for treating diabetes related complications [36](Fig 1).

\section{Conclusion}

The occurrence and development of COVID-19 infection depends on viral factors and host individual factors including genetics, age, gender, nutritional and health status [37-39]. 
Patients with associated comorbidities comprise a high risk group for coronavirus infection. The morbidity and mortality are higher in this high risk patients compared to normal individuals.

COVID-19 entry to the host cell depends on ACE2 receptor; therefore a potential treatment strategy for COVID-19 could be targeting the ACE2 receptor. However, it is likely to have negative impact on associated comorbidities namely diabetes and hypertension that are treated with ACE inhibitor [40]. In addition, ACEIs up regulate ACE2 which can accelerate viral uptake and colonization in host's cells[41]. Viral attachment to ACE2 via the spike protein results in ACE2 down-regulation and therefore excessive production of Ang II and lower level of Ang 1-7 which in turn leads to lung damage through Angotensin II receptor type I (AT1R) stimulation [20]. Therefore, AT1R blockers are suggested to lower the rate of complications and mortality in COVID-19 [20]. Moreover, there are currently many other therapeutic approaches such as recombinant soluble ACE2-less complications mainly in presence of comorbid conditions. All in all, serious efforts must be considered to choose effective treatment in COVID-19 infection particularly in people with diabetes.

\section{Declaration of interests}

The authors declare that they have no competing interests

\section{Acknowledgments}

None .

\section{References}

1. Chen, Z., et al., Distribution of the COVID-19 epidemic and correlation with population emigration from wuhan, China. Chinese medical journal, 2020.

2. Boldog, P., et al., Risk assessment of novel coronavirus COVID-19 outbreaks outside China. Journal of Clinical Medicine, 2020. 9(2): p. 571. 
3. Novel, C.P.E.R.E., The epidemiological characteristics of an outbreak of 2019 novel coronavirus diseases (COVID-19) in China. Zhonghua liu xing bing xue za zhi= Zhonghua liuxingbingxue zazhi, 2020. 41(2): p. 145.

4. de Wit, E., et al., SARS and MERS: recent insights into emerging coronaviruses. Nature Reviews Microbiology, 2016. 14(8): p. 523.

5. Paraskevis, D., et al., Full-genome evolutionary analysis of the novel corona virus (2019-nCoV) rejects the hypothesis of emergence as a result of a recent recombination event. Infection, Genetics and Evolution, 2020. 79: p. 104212.

6. Coronavirus disease 2019 (COVID-19) Situation Report - 53 WHO. https://www.who.int/docs/default-source/coronaviruse/situation-reports/20200313-sitrep-53covid-19.pdf?sfvrsn=adb3f72 2 .

7. Report of the WHO-China Joint Mission on Coronavirus Disease 2019 (COVID-19) 16- 24 February 2020 https://www.who.int/docs/default-source/coronaviruse/who-china-joint-mission-oncovid-19-final-report.pdf.

8. Chen, N., et al., Epidemiological and clinical characteristics of 99 cases of 2019 novel coronavirus pneumonia in Wuhan, China: a descriptive study. The Lancet, 2020. 395(10223): p. 507-513.

9. Deng, S.-Q. and H.-J. Peng, Characteristics of and Public Health Responses to the Coronavirus Disease 2019 Outbreak in China. Journal of Clinical Medicine, 2020. 9(2): p. 575.

10. Huang, C., et al., Clinical features of patients infected with 2019 novel coronavirus in Wuhan, China. The Lancet, 2020. 395(10223): p. 497-506.

11. Wang, D., et al., Clinical characteristics of 138 hospitalized patients with 2019 novel coronavirusinfected pneumonia in Wuhan, China. Jama, 2020.

12. Zhang, J.j., et al., Clinical characteristics of 140 patients infected by SARS-CoV-2 in Wuhan, China. Allergy, 2020.

13. Guan, W.-j., et al., Clinical characteristics of coronavirus disease 2019 in China. New England Journal of Medicine, 2020.

14. Letko, M.C. and V. Munster, Functional assessment of cell entry and receptor usage for lineage $B$ B-coronaviruses, including 2019-nCoV. bioRxiv, 2020.

15. Adedeji, A.O., et al., Novel inhibitors of severe acute respiratory syndrome coronavirus entry that act by three distinct mechanisms. Journal of virology, 2013. 87(14): p. 8017-8028.

16. Bernardi, S., et al., Update on RAAS modulation for the treatment of diabetic cardiovascular disease. Journal of diabetes research, 2016. 2016.

17. Li, G. and E. De Clercq, Therapeutic options for the 2019 novel coronavirus (2019-nCoV). 2020, Nature Publishing Group.

18. Hoffmann, M., et al., SARS-CoV-2 Cell Entry Depends on ACE2 and TMPRSS2 and Is Blocked by a Clinically Proven Protease Inhibitor. Cell, 2020.

19. $\mathrm{Xu}, \mathrm{H}$. , et al., High expression of ACE2 receptor of 2019-nCoV on the epithelial cells of oral mucosa. International Journal of Oral Science, 2020. 12(1): p. 1-5.

20. Gurwitz, D., Angiotensin receptor blockers as tentative SARS-CoV-2 therapeutics. Drug Development Research, 2020.

21. Wang, J., et al., The ACE2-Ang (1-7)-Mas receptor axis attenuates cardiac remodeling and fibrosis in post-myocardial infarction. Molecular medicine reports, 2017. 16(2): p. 1973-1981.

22. Vincent, M.J., et al., Chloroquine is a potent inhibitor of SARS coronavirus infection and spread. Virology journal, 2005. 2(1): p. 69.

23. Cortegiani, A., et al., A systematic review on the efficacy and safety of chloroquine for the treatment of COVID-19. Journal of Critical Care, 2020.

24. Sui, J., et al., Potent neutralization of severe acute respiratory syndrome (SARS) coronavirus by a human $m A b$ to $S 1$ protein that blocks receptor association. Proceedings of the National Academy of Sciences, 2004. 101(8): p. 2536-2541. 
25. Li, Y., et al., Extraordinary GU-rich single-strand RNA identified from SARS coronavirus contributes an excessive innate immune response. Microbes and infection, 2013. 15(2): p. 88-95.

26. Zhang, H. and A. Baker, Recombinant human ACE2: acing out angiotensin II in ARDS therapy. 2017, Springer.

27. Foureaux, G., et al., Activation of endogenous angiotensin converting enzyme 2 prevents early injuries induced by hyperglycemia in rat retina. Brazilian Journal of Medical and Biological Research, 2015. 48(12): p. 1109-1114.

28. Yan, R., et al., Structural basis for the recognition of the SARS-CoV-2 by full-length human ACE2. Science, 2020.

29. Batlle, D., M.J. Soler, and M. Ye, ACE2 and diabetes: ACE of ACEs? Diabetes, 2010. 59(12): $\mathrm{p}$. 2994-2996.

30. Chhabra, K.H., H. Chodavarapu, and E. Lazartigues, Angiotensin converting enzyme 2: a new important player in the regulation of glycemia. IUBMB life, 2013. 65(9): p. 731-738.

31. Bindom, S.M., et al., Angiotensin l-converting enzyme type 2 (ACE2) gene therapy improves glycemic control in diabetic mice. Diabetes, 2010. 59(10): p. 2540-2548.

32. Chamsi-Pasha, M.A., Z. Shao, and W.W. Tang, Angiotensin-converting enzyme 2 as a therapeutic target for heart failure. Current heart failure reports, 2014. 11(1): p. 58-63.

33. Tikellis, C. and M. Thomas, Angiotensin-converting enzyme 2 (ACE2) is a key modulator of the renin angiotensin system in health and disease. International journal of peptides, 2012. 2012.

34. Harris, R.C., Podocyte ACE2 protects against diabetic nephropathy. Kidney international, 2012. 82(3): p. 255-256.

35. Verma, A., et al., ACE2 and Ang-(1-7) confer protection against development of diabetic retinopathy. Molecular therapy, 2012. 20(1): p. 28-36.

36. Verma, A., et al., Expression of human ACE2 in Lactobacillus and beneficial effects in diabetic retinopathy in mice. Molecular Therapy-Methods \& Clinical Development, 2019. 14: p. 161-170.

37. Qiu, R., et al., Outcome reporting from protocols of clinical trials of Coronavirus Disease 2019 (COVID-19): a review. medRxiv, 2020.

38. Wang, C., et al., A novel coronavirus outbreak of global health concern. The Lancet, 2020. 395(10223): p. 470-473.

39. Zhang, M., et al., Clinical features of 2019 novel coronavirus pneumonia in the early stage from a fever clinic in Beijing. Zhonghua jie he he hu xi za zhi= Zhonghua jiehe he huxi zazhi= Chinese journal of tuberculosis and respiratory diseases, 2020. 43: p. E013.

40. Estacio, R.O., et al., The effect of nisoldipine as compared with enalapril on cardiovascular outcomes in patients with non-insulin-dependent diabetes and hypertension. New England Journal of Medicine, 1998. 338(10): p. 645-652.

41. Huang, M.I., et al., Upregulation of angiotensin-converting enzyme (ACE) 2 in hepatic fibrosis by ACE inhibitors. Clinical and Experimental Pharmacology and Physiology, 2010. 37(1): p. e1-e6. 